TAO, Vol. 13, No. 3, 355-366, September 2002

\title{
Geodetically Observed Surface Displacements of the 1999 Chi-Chi Earthquake near Southern Termination of the Chelungpu Fault
}

\author{
Jih-Hao Hung ${ }^{1, *}$, Hai-Po Zhan ${ }^{1}$, David V. Wiltschko ${ }^{2}$, and Peng Fang ${ }^{3}$
}

(Manuscript received 21 May 2002, in final form 26 August 2002)

\begin{abstract}
Using the Global Positioning System (GPS) we investigated coseismic deformation in southwestern Taiwan for the Rayli $\left(7 / 7 / 1998, M_{L}=6.2\right)$, ChiChi $\left(9 / 21 / 1999, M_{L}=7.3\right)$ and Chiayi $\left(10 / 22 / 1999, M_{L}=6.4\right)$ earthquakes based on data collected from 1996 to 2001 . The GPS network includes 130 campaign-surveyed, 32 local tracking stations and 13 IGS (International GPS Service for Geodynamics) sites. The geodetic data were processed with GAMIT/GLOBK software. The results indicate that coseismic displacement vectors show opposite moving directions across the surface trace of the Chelungpu-Tachienshan-Chukou thrust fault. In general, the hanging-wall moves toward NW (or W, SW) as opposed to NE (or E, SE) for the footwall. The average amount of displacement is larger in the hanging-wall than in the footwall, with maximum displacement appearing at sties near the mainshock. An array of NW-SE trending left-lateral tear faults distributed in a zone of tens of kilometers wide are interpreted as transfer faults accommodating SW-directed, right-lateral thrusting in the vicinity of southern termination of the Chelungpu fault.
\end{abstract}

(Key words: GPS Geodesy, Chi-Chi Earthquake, Chelungpu fault)

\section{INTRODUCTION}

Southwestern Taiwan (Fig. 1) is an active zone under compression. Geodetic data (19901995) using the Global Positioning System (GPS) have shown that southwestern Taiwan is converging at a velocity ranging from $2.6 \mathrm{~mm} / \mathrm{yr}$ near the western coast to $4.0 \mathrm{~cm} / \mathrm{yr}$ east of the Chukou fault (CKF) at an approximate azimuth of $300^{\circ}$ relative to western offshore Penghu

\footnotetext{
${ }^{1}$ Institute of Geophysics, National Central University, Chungli, Taiwan , ROC

${ }^{2}$ Department of Geology and Geophysics and Center for Tectonophysics, Texas A\&M University, TX, USA

${ }^{3}$ Institute of Geophysics and Planetary Physics, Scripps Institution of Oceanography, University of California, San Diego, CA, USA

* Corresponding author address: Prof. Jih-Hao Hung, Institute of Geophysics, National Central University, Chung-Li, Taiwan, ROC; E-mail: t260001@cc.ncu.edu.tw
} 


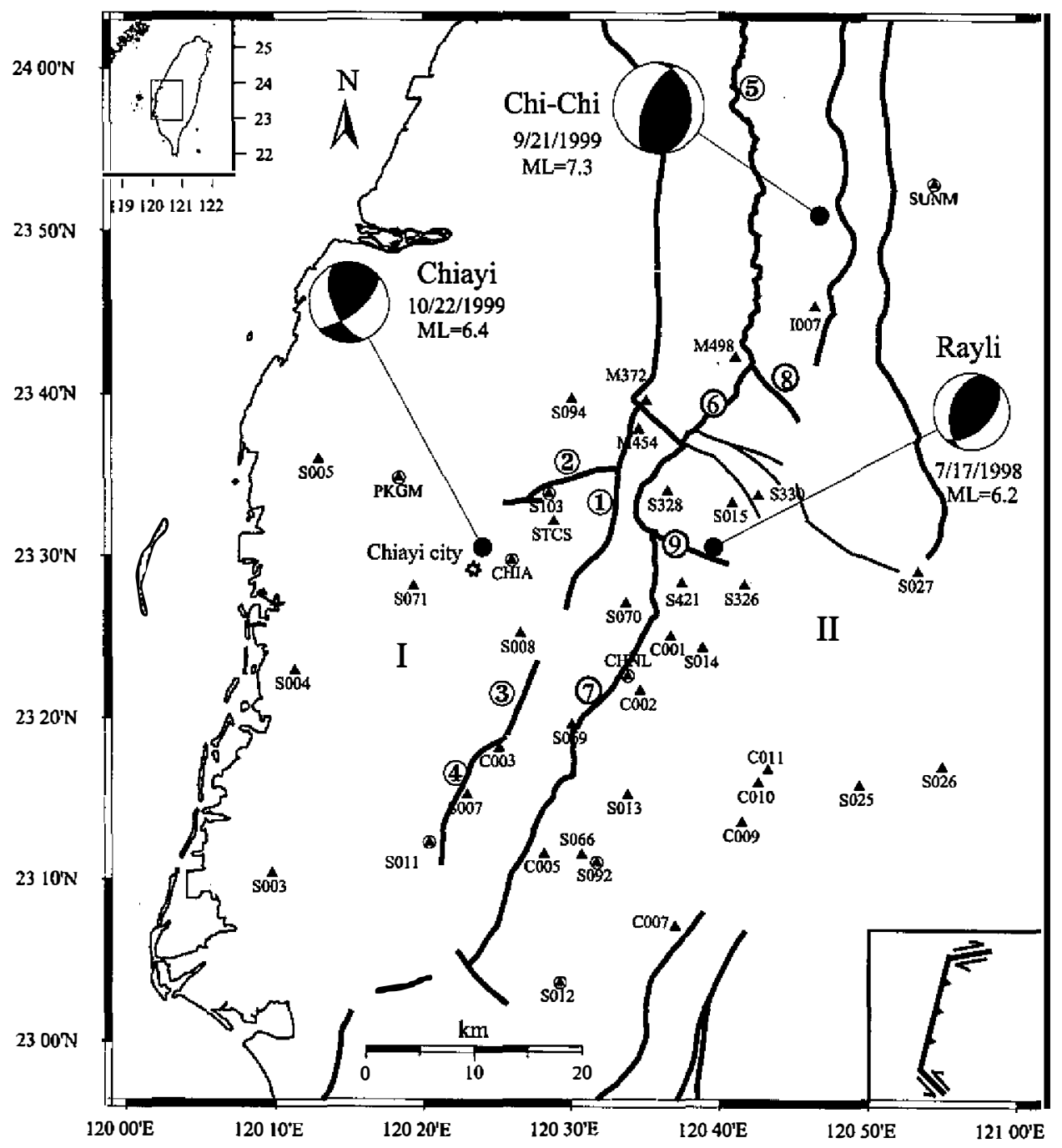

Fig. 1. Distribution of GPS sites and study area. Solid thick lines are major faults: 1. Chiuhsiungken; 2. Meishan; 3. Muchiliao; 4. Liaochia; 5. Chelungpu; 6. Tachienshan; 7. Chukou; 8. Luliao; 9. Shuisheliao. Thin solid lines between Lulioa and Shuisheliao faults are left-lateral tear faults. The Chelungpu-Tachienshan-Chukou fault is the boundary divides Coastal Plain (Region I) to the west and Western Foothills (Region II) to the east. Solid triangles are GPS sites of campaign mode, and others with circles outside are regional GPS tracking stations. Mainshocks of three major earthquakes occurred in this area are shown as black dots with corresponding focal mechanisms. The lower right inset shows the Chelungpu thrust terminate laterally at strike-slip zones from fault-plane solutions of Chi-Chi earthquake sequences. 
island (Yu and Chen 1998). Very high shortening rates (up to 3 mstrain/yr) appeared across the CKF and increased along the fault trace toward south (Yu and Chen 1998). Combining regional structural cross-sections with GPS data from 1996 to 1997, Hung et al. (1999) found that the CKF and other faults to the east are all active with internal strains widely distributed in the Foothills.

Three major hazardous earthquakes occurred in the study area since 1998 (Fig. 1). The Rayli earthquake $\left(1998 / 7 / 17, M_{L}=6.2\right)$ was the first in this region since the Paiho earthquake $\left(1964, M_{L}=6.5\right)$. The Chi-Chi earthquake $\left(1999 / 9 / 21, M_{L}=7.3\right)$ was the largest earthquake to strike the island in the 20th century. The Chiayi earthquake $\left(1999 / 10 / 22, M_{L}=6.4\right)$ triggered by the Chi-Chi earthquake occurred one month later in the west of the Chelungpu fault. These three earthquakes, particularly the Chi-Chi earthquake, produced significant horizontal and vertical displacements in southwestern Taiwan.

Using the GPS geodetic data surveyed at 285 stations over the whole island, Yang et al. (2000) calculated three-dimensional displacements of the Chi-Chi earthquake. Geodetic data from both GPS (Yu et al. 2001) and near-field techniques such as leveling and alignment arrays (Central Geologic Survey 1999, 2000; Lee et al. in review) all confirm that surface displacements in the hanging-wall of the Chelungpu fault increased from south toward the northern end of the Chi-Chi earthquake ruptures. Localized deformation and large coseismic displacements and slips at the ground surface (up to $10 \mathrm{~m}$ ) in the northern segment are interpreted to be related to the fault geometry and inherited Quatemary active structures (Hung and Suppe 2000; Wang 2000; Lee et al. 2002). In the central segment, coseismic displacement vectors point primarily toward the west and northwest. The southern end, unlike elsewhere in the hanging-wall, is characterized by oblique thrusting with right-lateral slips (maximum of 2 m) toward southwest (Central Geologic Survey 1999; Lee et al. in review). Conversely, earthquake focal mechanisms in the southern termination suggest a left-lateral slip on NW-trending nodal planes that extend about $50 \mathrm{~km}$ (Kao and Chen 2000). Surface ruptures and deformation indicated complex kinematics of the thrust block in the southern end of the Chelungpu fault and conflicting slip directions.

In this study, we used pre- and post-earthquake GPS geodetic data to quantify the coseismic surface displacement pattern of both the Rayli and Chi-Chi (including Chiayi) earthquakes. The resultant high precision coseismic displacement field allows us to understand fault kinematics during the Chi-Chi earthquake and structures to accommodate surface deformation.

\section{GPS DATA ACQUISITION AND PROCESSING}

GPS data were collected from 130 campaign sites in southern Taiwan annually in January and February from 1996 to 2001. Additional data were collected in 1998 after the Rayli earthquake and in 2000 after the Chi-Chi earthquake. Sites in southwestern Taiwan are mainly surveyed from 1996 to 2000 . We observed at least two (mostly in three) sessions of at least 8 hours per session for short baselines $(<15 \mathrm{~km})$ and greater than 24 hours for long baselines for each site during annual measurement. Each site is measured by dual-frequency geodetic GPS receivers (all Ashtech Z-XII in 1998 and Trimble 4000 SSE/SSI for the rest of years). 8 to 12 receivers were deployed simultaneously in each session, and dual-frequency observations were 
sampled every 15 seconds. Besides data from campaign-surveyed stations, global and regional permanent GPS tracking networks are included during the period of field surveys. Data from 13 IGS (International GPS Service for Geodynamics) sites and 32 local tracking stations over the island are also incorporated in the process. Local fiducial sites are maintained by various agencies including Academia Sinica (11 sites), Cen weal Wer Bureau (14 sites) and Minister of Interior (7 sites). 24hr continuous tracking data covering one day session were recorded every 30 seconds. Quasi-permanent stations are deployed to provide another set of daily solutions in order to reduce errors by averaging with the on-line tracking station data. A total data of nearly 3000 site-sessions were processed in this study.

Data processing was carried out in three steps. The first step is to process all data session by session using a weighted least square method in full-network mode with GAMIT 10.04 software developed at MIT (King and Bock 1995). The second step was to combine the session using a Kalman-filter with GLOBK 5.05 (Herring 1998). The last step was to analyze multi-year velocity vectors generated from the GLOBK solution to derive coseismic displacements.

In single session processing, raw data underwent an automatic treatment procedure of rejecting obvious outliers in observations as well as flags in cycle slips and gaps. The reated data were then used for forming double differences, which is the basic observables for a linear equation system, and unknown parameters can be solved using a weighted least-square method. To tie Taiwan regional sites into a global reference frame, 13 IGS global tracking stations in the vicinity were included in daily solutions. Coordination of those global sites defined as International Terrestrial Reference Frame 97 (ITRF97) at epoch 1998.0 was tightly constrained in the solution. Precise orbits from SIO (Scripps Institute of Oceanography) and EOP (Earth Orientation Parameters) consistent with ITRF97 were also tightly constrained in the process. Ionosphere-free phase combinations were formed to remove the first-order ionospheric effects. The Saastamoinen model (Saastamoinen 1972) was used to give nominal tropospheric delays on GPS phase measurements, and an hourly ropospheric zenith delay parameters at each site were estimated simultaneously using Niell's mapping function (Niell 1996) with elevation cutoff at 7 degree. Furthermore, IGS antenna phase center corrections and the solid earth tide correction terms are applied.

After data reduction of each daily sessions were completed, the variance/covariance matrices from all single session solutions were fed to GLOBK in which the multi-day site coordinate series were treated as continuous variables so that their velocities can be estimated in a consistent manner. In this step, tight constraints were applied to the well-known global sites, as well as EOP and orbital parameters.

GLOBK processing has been done in three stages. First, an annual solution without site velocity estimation was computed to identify observational blunders. The position time series coming from these solutions are used to check site qualities. Secondly, multi-year solutions among groups before and after the 1998 and 1999 earthquakes, respectively, are analyzed with global sites constrained and regional velocity estimated. Third, multi-year solutions without global constraints, i.e., the best fit of the regional data, were performed in order to check for common global error sources. We have compared the estimated rate of the third solution with the second type (multi-year with global constrain), and a good agreement between them im- 
plies that there is no significant error such as orbit/EOP or fiducial station problem.

Coseismic displacement of each site is defined by the differences in positions before and after earthquakes obtained by projecting measured positions to the day of earthquake through multi-year velocities. Multi-year site velocity can be estimated independently from the position time series (Fig. 2) if there are sufficient observations (at least two sessions per year for two years) before and after earthquakes, such as station CHIA. This method was applied to the Rayli earthquake for all sites and the Chi-Chi earthquake for continuous sites. Conversely, for the Chi-Chi earthquake, the pre-earthquake site velocity was used to compute the coseismic displacements since most campaign sites, such as C005 and S013 (Fig. 2), have only one year data after the Chi-Chi earthquake. Furthermore, after correcting the Rayli coseismic
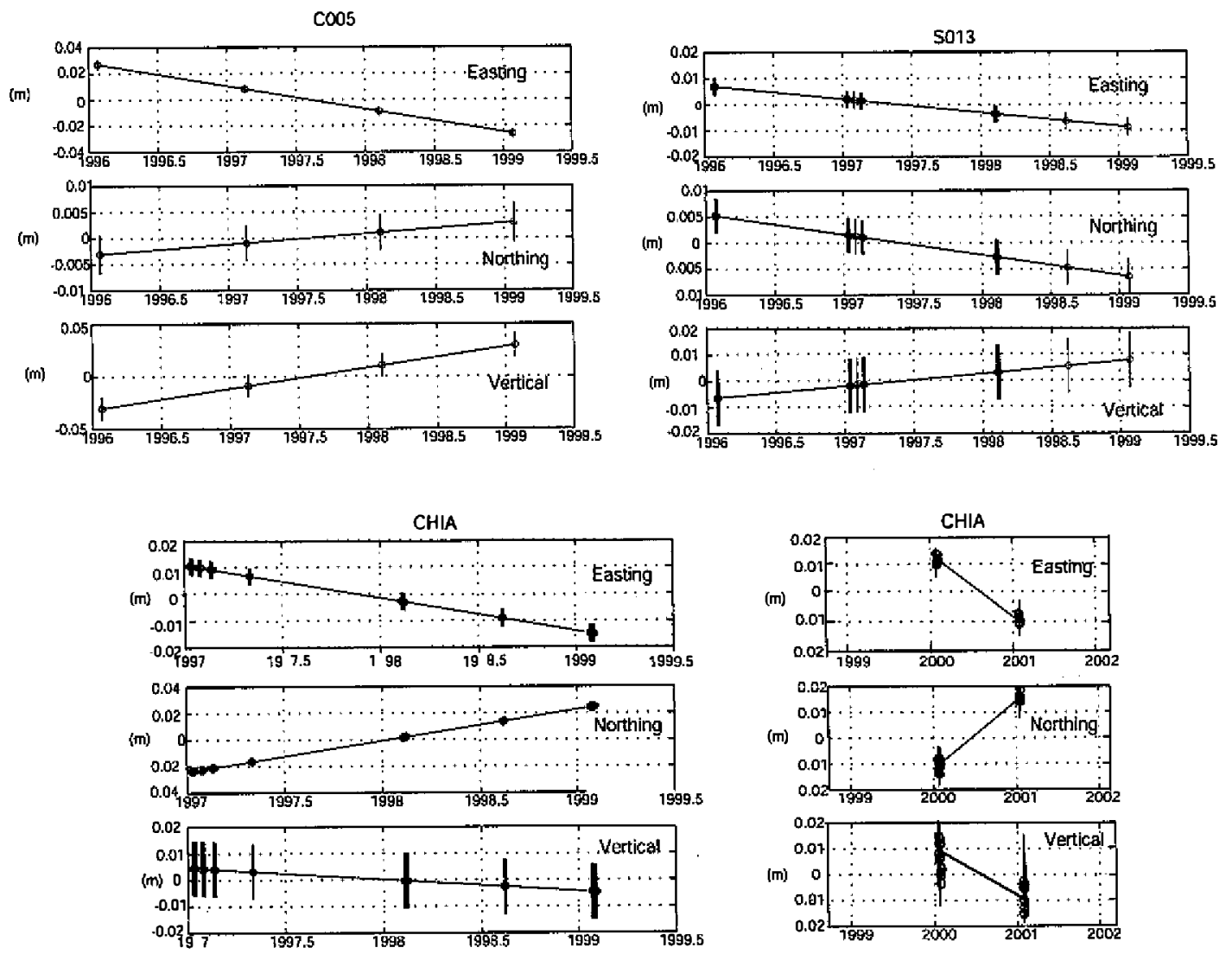

Fig. 2. Typical time series position of campaign-surveyed stations (C005, S013) and a local continuous recording station (CHIA) showing the error bars and variations on east, north and height changes. The straight line in each plot is the best fitting line. Site velocities are estimated independently before and after the Chi-Chi earthquakes at CHIA, whereas only pre-earthquake velocities are obtained at campaign stations. Coseismic displacements of the Rayli earthquake are minor in these stations. 
displacements, the computed Chi-Chi coseismic displacements also include motion accompanying the Chiayi earthquake because there is no survey between them.

\section{RESULTS}

Horizontal surface displacements of the Rayli earthquake from 33 stations in the study area were estimated relative to Paisha, Penghua (S01R), which is considered to be part of the Eurasian Continent. The east and north components of displacement vectors and associated sigma values are listed in Table 1. In general, surface displacements are relatively small (less than $3 \mathrm{~cm}$ ), and more than half of the sites show displacements smaller than their corresponding 1-sigma error ranges. Sites located on the hanging-wall of the Tachienshan-Chukou fault and sites near the epicenter, such as S326, S328 and S027, show relatively higher displacement and move toward west and northwest. Motion of these sites implies a thrust-type mechanism which is compatible with the fault-plane solution shown in Fig. 1.

The three dimensional coseismic displacement field was sampled for the Chi-Chi earthquake from 33 stations with $95 \%$ confidence errors (or 2-sigmas) ranging from 0.31 to 0.67 $\mathrm{cm}$ in the east-west direction, 0.32 to $0.83 \mathrm{~cm}$ in the north-south direction, and 0.98 to $2.93 \mathrm{~cm}$ in the vertical direction. The amount of displacements and their corresponding statistical errors are listed in Table 2. Figures 3 and 4 illustrate the spatial distribution of horizontal and vertical coseismic displacement vectors. In the vicinity of the mainshock, the displacement pattern is similar to the results of previous studies (for example, Yang et al. 2000), i.e., hanging-wall sites moved toward the west or northwest and footwall sites moved toward the east or southeast. Among them, I007 shows the largest displacement of $1.32 \mathrm{~m}$ toward $304^{\circ}$ direction, and M498 displaced $0.93 \mathrm{~m}$ toward $91^{\circ}$. Sites in the hanging-wall of the Tachienshan-Chukou fault and away from the termination of surface ruptures, such as S326, S015, S328, S421 and S014, displace toward southwest with decreasing displacement from north to south. The southwest-directed motion agrees with field studies at the end of surface ruptures. An averaged 1.4 $\mathrm{m}$ of apparent right-lateral motion with $50 \mathrm{~cm}$ of uplift is observed at Lindin tea garden near Tungtou village (NCREE 1999; Lee et al. 2002).

In general, individual sites in the footwall subsided to a maximum of $1.16 \mathrm{~m}$ at M498, based on previous results from other parts of the Chelungpu fault. On the other hand, irregular uplift and subsidence occurred in the hanging-wall, among which I007 and CHNL uplifted about $75 \mathrm{~cm}$ and $13 \mathrm{~cm}$ respectively, and both $S 027$ and $S 328$ subsided about $23 \mathrm{~cm}$. The remaining sites show relatively minor vertical motion. The lack of systematic vertical change is also seen in previous studies (e.g., Yang et al. 2000). Further analysis will be needed to understand mechanisms affecting local variations.

\section{DISCUSSION}

The pattern of coseismic displacement vectors of the Rayli earthquake in our analysis coincides with that of Yu et al. (1998), in which individual stations displaced from 3 to $26 \mathrm{~mm}$ and 9 to $28 \mathrm{~mm}$, respectively. The error values are relatively high compared to the amount of displacement (Table 1), possibly due to: 1) most stations have only two years of data before 
Table 1. Horizontal coseismic displacements of the Rayli earthquake and associated sigma values.

\begin{tabular}{|c|c|c|c|c|c|c|c|c|}
\hline Station & Lon. $\left({ }^{\circ} \mathrm{E}\right)$ & Lat. $\left({ }^{\circ} \mathrm{N}\right)$ & $\mathrm{dE}(\mathrm{mm})$ & $\sigma_{\mathrm{E}}(\mathrm{mm})$ & $\mathrm{dN}(\mathrm{mm})$ & $\sigma_{N}(\mathrm{~mm})$ & $\mathrm{S}(\mathrm{mm})$ & Az. $\left(\left(^{\circ}\right)\right.$ \\
\hline \multicolumn{9}{|c|}{ Hanging-wall } \\
\hline $\mathrm{C} 001$ & 120.6120 & 23.4180 & -13.0 & 3.6 & -1.0 & 3.4 & 13.0 & 266 \\
\hline $\mathrm{CO02}$ & 120.5770 & 23.3620 & -3.0 & 4.2 & -3.0 & 4.0 & 4.2 & 225 \\
\hline C005 & 120.4690 & 23.1930 & -9.0 & 3.9 & 2.0 & 3.6 & 9.2 & 283 \\
\hline C007 & 120.6170 & 23.1190 & 9.0 & 3.2 & 18.0 & 3.1 & 20.1 & 27 \\
\hline C009 & 120.6930 & 23.2260 & 3.0 & 3.3 & 2.0 & 3.1 & 3.6 & 56 \\
\hline $\mathrm{C} 010$ & 120.7110 & 23.2660 & 7.0 & 3.2 & 3.0 & 3.0 & 7.6 & 67 \\
\hline C011 & 120.7220 & 23.2800 & -3.0 & 3.8 & 3.0 & 3.4 & 4.2 & 315 \\
\hline I007 & 120.7740 & 23.7560 & 3.0 & 9.8 & 3.0 & 8.7 & 4.2 & 45 \\
\hline S012 & 120.4880 & 23.0590 & -6.0 & 2.3 & 6.0 & 2.2 & 8.5 & 315 \\
\hline S013 & 120.5640 & 23.2540 & 2.0 & 2.6 & -3.0 & 2.6 & 3.6 & 146 \\
\hline S014 & 120.6490 & 23.4040 & -4.0 & 3.2 & -6.0 & 3.2 & 7.2 & 214 \\
\hline S025 & 120.8240 & 23.2640 & -3.0 & 3.8 & 9.0 & 3.6 & 9.5 & 342 \\
\hline S026 & 120.9160 & 23.2820 & 0.1 & 4.2 & 3.0 & 4.0 & 3.0 & 2 \\
\hline S027 & 120.8900 & 23.4840 & -14.0 & 4.9 & 13.0 & 4.9 & 19.1 & 313 \\
\hline S092 & 120.5280 & 23.1850 & 12.0 & 3.4 & 2.0 & 3.1 & 12.2 & 81 \\
\hline S326 & 120.6950 & 23.4700 & -23.0 & 7.6 & 1.0 & 5.9 & 23.0 & 272 \\
\hline S328 & 120.6080 & 23.5670 & -13.0 & 6.7 & 12.0 & 6.6 & 17.7 & 313 \\
\hline S330 & 120.7100 & 23.5620 & -4.0 & 10.0 & 4.0 & 10.0 & 5.7 & 315 \\
\hline SUNM & 120.9080 & 23.8810 & 2.0 & 1.8 & 4.0 & 1.8 & 4.5 & 153 \\
\hline \multicolumn{9}{|l|}{ Footwall } \\
\hline $\mathrm{C} 003$ & 120.4190 & 23.3020 & 23.0 & 5.8 & 12.0 & 5.4 & 25.9 & 62 \\
\hline CHIA & 120.4330 & 23.4960 & 5.0 & 1.5 & -1.0 & 1.5 & 5.1 & 101 \\
\hline M372 & 120.5840 & 23.6600 & 0.1 & 10.0 & -7.0 & 9.1 & 7.0 & 179 \\
\hline M454 & 120.576 & 23.6310 & -11.0 & 6.8 & 12.0 & 6.4 & 16.3 & 317 \\
\hline M498 & 120.6890 & 23.6900 & -6.0 & 6.9 & 3.0 & 6.5 & 6.7 & 297 \\
\hline S007 & 120.3830 & 23.2540 & -4.0 & 3.2 & 5.0 & 3.0 & 6.4 & 321 \\
\hline S008 & 120.4440 & 23.4200 & 6.0 & 3.0 & -2.0 & 3.1 & 6.3 & 108 \\
\hline S011 & 120.3390 & 23.2050 & 1.0 & 1.4 & 3.0 & 1.4 & 3.2 & 18 \\
\hline S069 & 120.5010 & 23.3260 & -5.0 & 2.6 & -2.0 & 2.6 & 5.4 & 248 \\
\hline S070 & 120.5620 & 23.4520 & -4.0 & 4.2 & -10.0 & 3.8 & 10.8 & 202 \\
\hline S071 & 120.3220 & 23.4690 & 9.0 & 6.4 & 0.1 & 6.0 & 9.0 & 89 \\
\hline S094 & 120.5020 & 23.6610 & 5.0 & 6.1 & -2.0 & 6.3 & 5.4 & 112 \\
\hline S103 & 120.4750 & 23.5640 & 7.0 & 1.2 & -2.0 & 1.2 & 7.3 & 106 \\
\hline STCS & 120.4810 & 23.5360 & 7.0 & 3.5 & 2.0 & 3.3 & 7.3 & 74 \\
\hline
\end{tabular}

Note: $\mathrm{dE}$ and $\mathrm{dN}$ are east and north components of coseismic displacements; S: coseismic horizontal displacement; Az: azimuth of $\mathrm{S} . \sigma_{\mathrm{E}}$ and $\sigma_{\mathrm{N}}$ are one standard deviation.

and after earthquake, and 2) the hypocenter is deeper than calculated $(8 \mathrm{~km})$ thus the measured coseismic displacement is relatively insignificant compared to the errors.

The Chi-Chi coseismic displacements have been estimated by other studies (Yang et al. 2000; Yu et al. 2001). Nevertheless, the surface kinematics at the southern end of the surface ruptures have not been well studied because the displacements are relatively small compared 
Table 2. Coseismic displacements of the Chi-Chi earthquake and associated statistical errors.

\begin{tabular}{|c|c|c|c|c|c|c|c|c|c|c|}
\hline station & $\begin{array}{l}\text { Lon } \\
\left({ }^{\circ} \mathrm{E}\right)\end{array}$ & $\begin{array}{l}\text { Lat } \\
\left({ }^{\circ} \mathrm{N}\right)\end{array}$ & $\begin{array}{c}\mathrm{dE} \\
(\mathrm{cm})\end{array}$ & $\begin{array}{c}\mathrm{dN} \\
(\mathrm{cm})\end{array}$ & $\begin{array}{c}\mathrm{dV} \\
(\mathrm{cm})\end{array}$ & $\begin{array}{l}\alpha_{95} E \\
(\mathrm{~cm})\end{array}$ & $\begin{array}{l}\alpha_{95} \mathrm{~N} \\
(\mathrm{~cm})\end{array}$ & $\begin{array}{l}\alpha_{95} V \\
(\mathrm{~cm})\end{array}$ & $\begin{array}{c}S \\
(\mathrm{~cm})\end{array}$ & $\begin{array}{l}\mathrm{Az} \\
\mathrm{C})\end{array}$ \\
\hline \multicolumn{11}{|c|}{ Hanging-wall } \\
\hline $\mathrm{COO} 1$ & 120.61 & 23.42 & -4.9 & -5.0 & -5.1 & 0.4 & 0.4 & 1.3 & 7.0 & 224 \\
\hline C005 & 120.47 & 23.19 & 0.2 & -2.1 & 0.0 & 0.4 & 0.4 & 1.2 & 2.1 & 175 \\
\hline $\mathrm{C} 007$ & 120.62 & 23.12 & -0.1 & -0.5 & -4.6 & 0.3 & 0.4 & 1.2 & 0.5 & 192 \\
\hline C009 & 120.69 & 23.23 & -1.6 & -1.6 & -2.1 & 0.3 & 0.4 & 1.2 & 2.3 & 226 \\
\hline $\mathrm{C} 010$ & 120.71 & 23.27 & -2.4 & -2.9 & -3.4 & 0.3 & 0.4 & 1.2 & 3.8 & 220 \\
\hline CHNL & 120.56 & 23.38 & -1.5 & -2.3 & 13.4 & 0.5 & 0.7 & 2.3 & 2.7 & 213 \\
\hline I007 & 120.77 & 23.76 & -109.7 & 72.8 & 75.4 & 0.7 & 0.8 & 3.0 & 131.6 & 304 \\
\hline S012 & 120.49 & 23.06 & -2.3 & -0.6 & -3.2 & 0.3 & 0.4 & 1.2 & $2: 4$ & 256 \\
\hline S013 & 120.56 & 23.25 & 0.2 & -3.6 & -1.4 & 0.3 & 0.3 & 1.2 & 3.6 & 177 \\
\hline S014 & 120.65 & 23.4 & -5.3 & -5.8 & -3.5 & 0.3 & 0.3 & 1.2 & 7.9 & 222 \\
\hline S015 & 120.68 & 23.56 & -12.8 & -16.6 & 9.2 & 0.5 & 0.8 & 2.3 & 21.0 & 218 \\
\hline S025 & 120.82 & 23.26 & -1.4 & -0.3 & -5.9 & 0.3 & 0.4 & 1.3 & 1.5 & 257 \\
\hline S026 & 120.92 & 23.28 & -4.4 & 5.4 & -3.2 & 0.3 & 0.3 & 1.1 & 7.0 & 321 \\
\hline S027 & 120.89 & 23.48 & -31.8 & 29.2 & -23.2 & 0.4 & 0.4 & 1.4 & 43.2 & 313 \\
\hline S092 & 120.53 & 23.18 & -0.7 & -2.3 & -3.0 & 0.4 & 0.4 & 1.4 & 2.4 & 197 \\
\hline S326 & 120.69 & 23.47 & -6.8 & -10.7 & 0.39 & 0.4 & 0.4 & 1.4 & 12.7 & 212 \\
\hline S328 & 120.61 & 23.57 & -7.6 & -19.6 & -23.17 & 0.5 & 0.6 & 2.2 & 21.0 & 201 \\
\hline S421 & 120.60 & 23.46 & -1.3 & -14.3 & -1.57 & 0.3 & 0.4 & 1.2 & 14.3 & 185 \\
\hline \multicolumn{11}{|c|}{ Footwall } \\
\hline $\mathrm{CO03}$ & 120.42 & 23.30 & 0.7 & -2.4 & -12.3 & 0.4 & 0.4 & 1.3 & 2.5 & 165 \\
\hline CHIA & 120.43 & 23.50 & 2.2 & -2.1 & 4.1 & 0.3 & 0.3 & 1.0 & 3.1 & 134 \\
\hline M372 & 120.58 & 23.66 & 17.6 & -2.9 & -16.3 & 0.4 & 0.5 & 1.8 & 18.0 & 99 \\
\hline M454 & 120.58 & 23.63 & 21.1 & -1.5 & -7.4 & 0.5 & 0.7 & 2.0 & 21.2 & 94 \\
\hline M498 & 120.69 & 23.69 & 93.0 & -1.1 & -115.8 & 0.5 & 0.7 & 2.0 & 93.0 & 91 \\
\hline N625 & 120.78 & 23.18 & -2.6 & -0.6 & -6.8 & 0.4 & 0.4 & 1.3 & 2.7 & 256 \\
\hline PKGM & 120.31 & 23.58 & 8.1 & -2.7 & -2.0 & 0.4 & 0.5 & 1.4 & 8.6 & 109 \\
\hline S007 & 120.38 & 23.25 & 1.5 & -1.4 & -5.0 & 0.3 & 0.4 & 1.1 & 2.0 & 131 \\
\hline S008 & 120.44 & 23.42 & 1.0 & -4.6 & -3.5 & 0.3 & 0.4 & 1.2 & 4.7 & 168 \\
\hline S011 & 120.34 & 23.21 & 1.3 & -1.0 & -9.4 & 0.3 & 0.3 & 1.0 & 1.7 & 128 \\
\hline S069 & 120.50 & 23.33 & -1.9 & -3.3 & -2.7 & 0.3 & 0.4 & 1.2 & 3.8 & 209 \\
\hline S070 & 120.56 & 23.45 & -1.9 & -4.6 & -8.7 & 0.5 & 0.6 & 2.3 & 5.0 & 203 \\
\hline S094 & 120.50 & 23.66 & 16.6 & -1.9 & -7.81 & 0.4 & 0.4 & 1.3 & 16.7 & 97 \\
\hline S103 & 120.48 & 23.56 & 6.8 & -1.3 & -0.60 & 0.3 & 0.3 & 1.0 & 7.0 & 101 \\
\hline STCS & 120.48 & 23.54 & 3.66 & -0.62 & -5.73 & 0.42 & 0.51 & 1.70 & 3.71 & 100 \\
\hline
\end{tabular}

Note: $\mathrm{dN}, \mathrm{dE}$ and $\mathrm{dV}$ : north, east and vertical components, respectively, of coseismic displacements; S: coseismic horizontal displacement; Az: azimuth of $\mathrm{S}$. The uncertanities are $95 \%$ confidence errors.

to other segments. A few common stations including local continuous recording and campaign-surveyed stations (such as I007, M372, M454, S027, S070, S326, S328 and S421 in Fig. 1) have been sampled in this and previous studies. Both magnitude and azimuth of displace- 


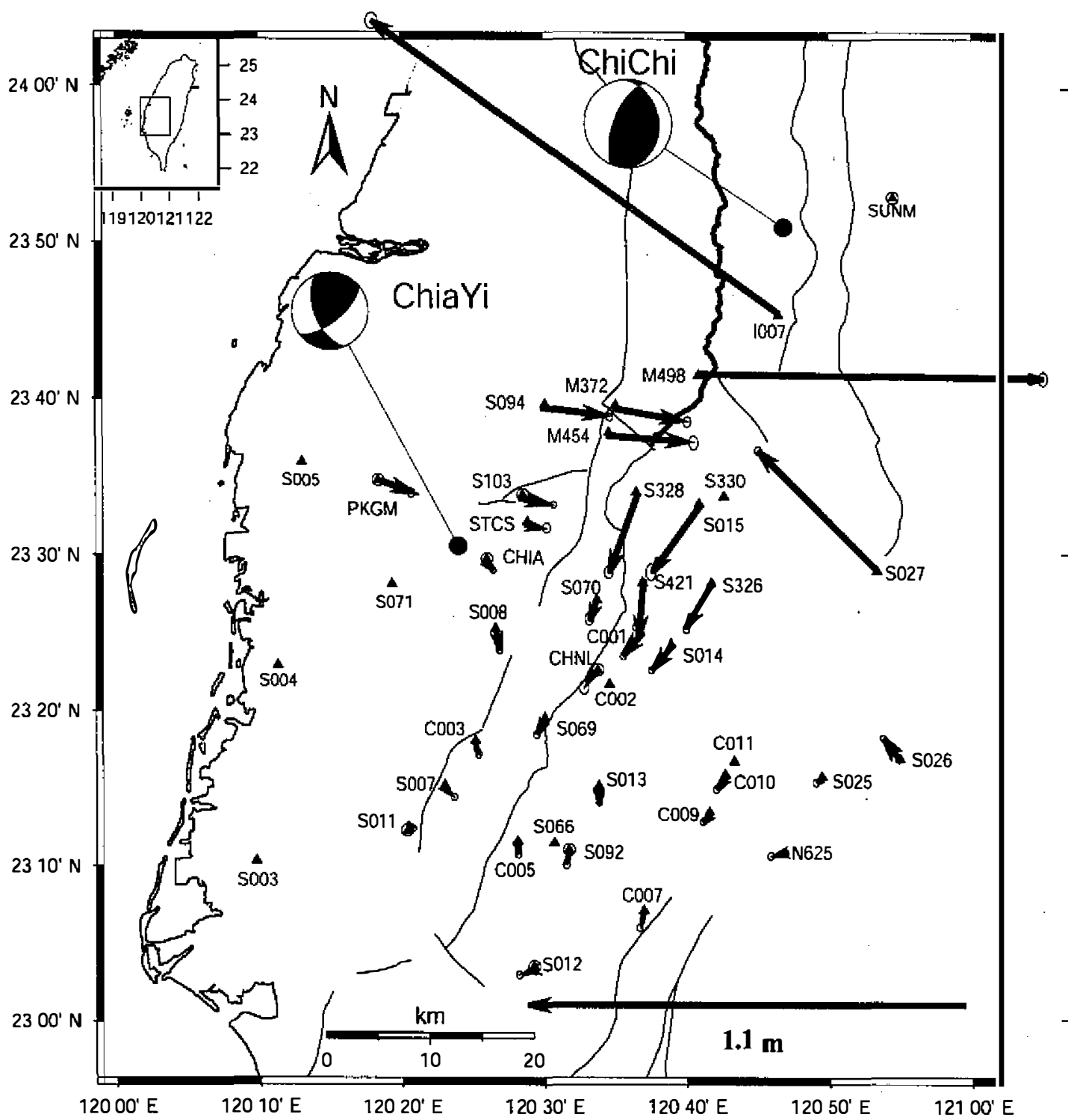

Fig. 3. Horizontal coseismic displacement vectors of GPS stations during the Chi-Chi earthquake. Arrowhead is $95 \%$ confidence error ellipse. Thickline is surface ruptures of the Chi-Chi earthquake. See Fig. 1 for fault names.

ment vectors estimated in our analysis are in good agreement with previous studies. For example, 1007 has displaced $1.3 \mathrm{~m}$ toward $304^{\circ}$ in our analysis compared to $1.1 \mathrm{~m}$ toward $313^{\circ}$ by $\mathrm{Yu}$ et al. (2001, their table 4); coseismic displacements of sites S326, S328 and S421 with southwest-directed motion are also in concert with those analyzed by Yang et al. (2000) for both horizontal and vertical motion. Stations in our study area were surveyed 4 months after the 
Hung, J., D. V. Wiltschko, H. C. Lin, J. H. Hickman, P. Fang, and Y. Bock, 1999: Structure and motion of the southwestern Taiwan Fold and Thrust belt. TAO, 10, 543-568.

Hung, J., and J. Suppe, 2000: Subsurface geometry of the Chelungpu fault and surface deformation style. Proceeding of International Workshop on Annual Commemoration of Chi-Chi Earthquake. Loh and Liao (Eds.) V.1- Science Aspect. NCREE, Taipei, Taiwan, 133-144.

Kao, H., and W. P. Chen, 2000: The Chi-Chi earthquake sequence: active, out-of-sequence thrust faulting in Taiwan. Science, 288, 2346-2439.

King, R. W., and Y. Bock, 1995: Documentation of the GAMIT GPS Analysis Software version 9.3, Mass. Inst. Tech., Cambridge.

Lee, J. C., H. T. Chu, J. Angelier, Y. C. Chan, J. C. Hu, C. Y. LU, and R. J. Rau, 2002: Geometry and structure of northern surface ruptures of the $1999 \mathrm{Mw}=7.6 \mathrm{Chi}-\mathrm{Chi}$ Taiwan earthquake: influence from inherited fold belt structures. J. Struct. Geol., 24, 173-192.

Lee, Y. H., W. Y. Wu, T. S. Shih, S. D. Lu, and M. L. Hsieh, in review: Measurements of slip vectors on the surface rupture of the 1999 Chi-Chi earthquake, western Taiwan.

Lee, Y. H., S. D. Lu, and T. S. Shih, 2002: Deformation mechanism of the southern ending of the Chi-Chi earthquake- the TFF triple-junction model. Bull. Central Geol. Survey, 15. (in Chinese).

Liu, H.C., and C. F. Lee, 1998: Geological Map of Taiwan, YULIN sheet, Scale 1:50,000. Central Geological Survey, MOEA. Taipei, Taiwan, ROC.

Ma, K. F., C. T. Lee, and Y. B. Tsai, 1999: The Chi-Chi, Taiwan Earthquake: large surface displacements on an inland thrust fault. EOS, 80, 605.

National Center for Research on Earthquake Engineering, 1999: Report of the hazard investigation for the 921 Chi-Chi earthquake- Geological Aspect. NCREE-99-051. 113pp.

Saastamoinen, J., 1972: Atmospheric correction for the troposphere and stratosphere in ranging of satellites, in the use of artificial satellites for geodesy. Geophys. Monogr. Ser., 15, 247-251.

Wang, C. Y., 2000: Investigation of subsurface structures of the Chelungpu fault by the seismic reflection method. Proceeding of International Workshop on Annual Commemoration of Chi-Chi Earthquake. Loh and Liao (Eds.), V.1- Science Aspect. NCREE, Taipei, Taiwan, 111-122.

Yang, M., R. J. Rau, J. Y. Yu, and T. T. Yu, 2000: Geodetically observed surface displacements of the 1999 Chi-Chi, Taiwan, earthquake. Earth Planets Space, 52, 403-413.

Yu, S. B., and H. Y. Chen, 1998: Strain accumulation in southwestern Taiwan. TAO, 9, 31-50.

Yu, S. B., L. C. Kuo, and C. H. Yen, 1998: Coseismic diplacements of the Rayli earthquake. $7^{\text {th }}$ Geophysical Annual Meeting of Taiwan, abstract w/program, 23-32.

Yu, S. B., L. C. Kuo, Y. J. Hsu, H. H. Su, and C. C. Liu, 2001: Preseismic deformation and coseismic displacements associated with the 1999 Chi-Chi, Taiwan, earthquake. Bull. Seism. Soc. Am., 91, 995-1012.

Zhan, H. P., 2000: Crustal deformation in Chinan area, southwestern Taiwan, 1996-2000 from GPS geodesy. $\mathrm{M}_{\mathrm{SC}}$ thesis, National Central University, 182pp. (in Chinese). 